\title{
Apigenin inhibits the self-renewal capacity of human ovarian cancer SKOV3-derived sphere-forming cells
}

\author{
AI-QIONG TANG ${ }^{1 *}$, XIAO-CHENG CAO ${ }^{2 *}$, LI TIAN $^{2}$, LIHUA HE $^{2}$ and FEI LIU ${ }^{2}$ \\ ${ }^{1}$ Department of Gynaecology and Obstetrics, The Maternal and Child Health Hospital of Hunan Province, \\ Changsha, Hunan $410008 ;{ }^{2}$ Laboratory of Medicine Engineering, Medical College, \\ Hunan Normal University, Changsha, Hunan 410013, P.R. China
}

Received January 23, 2014; Accepted October 31, 2014

DOI: $10.3892 / \mathrm{mmr} .2014 .2974$

\begin{abstract}
Casein kinase 2 (CK2) is a protein kinase which is frequently activated in cancer. The Hedgehog $(\mathrm{Hh})$ signaling pathway is involved in the stimulation of cancer stem cell growth. Its aberrant activation has been validated in several types of cancer, including ovarian cancer. In the present study, the sphere-forming cells (SFCs) of the human ovarian cancer SKOV3 cell line were observed to have self-renewal capacity, indicating the possession of ovarian cancer stem-like cell properties. SKOV3-derived SFCs had higher levels of CK2 $\alpha$ and glioma-associated oncogene 1 (Gli1) proteins compared with those of parental cells. Apigenin, a common flavonoid, significantly inhibited the self-renewal capacity and the protein expression of CK2 $\alpha$ and Gli1 proteins in the SKOV3-derived SFCs, which occurred in a concentration-dependent manner. In addition, CK $2 \alpha$ small interfering RNA downregulated the protein expression of CK2 $\alpha$ and Gli1 and synergistically inhibited the self-renewal capacity of the SKOV3-derived SFCs with apigenin. However, forced overexpression of CK $2 \alpha$ resulted in an increase in the expression of CK2 $\alpha$ and Gli1 and attenuated the apigenin-inhibited self-renewal effect in the SKOV3-derived SFCs. These results suggested that apigenin inhibited the self-renewal capacity of SKOV3-derived SFCs and was involved in downregulating the expression of Gli1 by the inhibition of CK $2 \alpha$.
\end{abstract}

\section{Introduction}

The protein kinase casein kinase 2 (CK2) is a highly conserved serine/threonine kinase with a broad spectrum

Correspondence to: Dr Fei Liu, Laboratory of Medicine Engineering, Medical College, Hunan Normal University, 371 Tongzipo Road, Changsha, Hunan 410013, P.R. China

E-mail: liufei5460@126.com

*Contributed equally

Key words: ovarian cancer, cancer stem cells, apigenin, casein kinase $2 \alpha$, glioma-associated oncogene 1 , self-renewal of substrates (1). CK2 is a multifunctional protein kinase and is involved in cell proliferation and survival (2-4). An increase in the levels and activity of CK $2 \alpha$ has been observed in several types of human cancer, including ovarian cancer $(5,6)$. CK2 also affects several cell signaling pathways, including those of phosphoinositide 3-kinase, nuclear factor- $\kappa \mathrm{B}$ and Wnt (7-9). A previous study revealed that Hedgehog (Hh)/glioma-associated oncogene (Gli) signaling is downregulated following inhibition of CK2, with a subsequent reduction in the number of stem-like side population cells in human lung cancer cells (10).

Sonic hedgehog (Shh), a member of the Hh family of proteins, consists of secreted signaling molecules and has several functions during vertebrate development (11). Activation of the Hh pathway is initiated at the cell surface, in which the Hh ligand binds to its receptor Patched. This leads to the removal of repression of the effector protein Smoothened (Smo), a G-protein-coupled receptor (12). Ultimately, Smo activates the Gli family of transcription factors and its target genes and Glil activates the Hh target genes $(13,14)$. Deregulation of $\mathrm{Hh} / \mathrm{Gli}$ signaling is considered to be an initiating or maintaining factor in the progression of various types of cancer, including ovarian cancer $(13,15)$. The Gli1 gene is amplified in human glioma and is activated in basal cell carcinoma $(16,17)$ and in ovarian cancer stem-like cells (18). These findings suggest that investigation of the pharmacological inhibitors of the Shh pathway may be beneficial in the treatment and/or prevention of ovarian cancer.

Apigenin is chemically known as 4',5,7,-trihydroxyflavone and has the molecular formula $\mathrm{C}_{5} \mathrm{H}_{10} \mathrm{O}_{5}$, with a molecular weight of $270 \mathrm{~g} / \mathrm{mol}$. Apigenin has been observed to have marked effects in inhibiting cancer cell growth in cell culture systems and in in vivo tumor models $(19,20)$. Apigenin has also been demonstrated to inhibit tumor cell invasion and metastasis (21) and suppress mitogen-activated protein kinases and downstream oncogene expression (22). These findings suggest that apigenin possesses significant preventative effects against cancer. In addition, a previous study by our group demonstrated that apigenin affected the number of glioma stem-like cells derived from U251 cells (23), implying the potential of apigenin to interfere with cancer stem cells. However, whether apigenin affects the self-renewal capacity 
of ovarian cancer stem-like cells (OCSLCs) and its underlying mechanisms of action remain to be elucidated.

The present study investigated the self-renewal capacity, a main feature for identifying OCSLCs, of sphere-forming cells (SFCs) of the human ovarian cancer cell line SKOV3. The effect of apigenin on the self-renewal capacity of SKOV3-derived SFCs and the involvement of CK2 $\alpha$ and the Hedgehog signaling pathway in this process were studied. The results provide important evidence for the potential benefits of CK2 inhibitors, including apigenin, in the treatment of ovarian cancer.

\section{Materials and methods}

Reagents. Apigenin was obtained from Sigma-Aldrich (St. Louis, MO, USA) and was dissolved in dimethyl sulfoxide to a final concentration of $0.1 \%$ in media without causing cytotoxicity. The following reagents were purchased: anti-CK2 $\alpha$ (Millipore, Billerica, MA, USA), anti-Gli1 (Cell Signaling Technology, Inc., Beverly, MA, USA), anti- $\beta$-actin (Sigma-Aldrich), Dulbecco's modified Eagle's medium (DMEM; Invitrogen Life Technologies, Carlsbad, CA, USA) and fetal bovine serum (Invitrogen Life Technologies). All other chemicals were obtained from Sigma-Aldrich.

Cell culture and tumorsphere formation assay. The human ovarian cancer SKOV3 cells (American Type Culture Collection, Manassas, VA, USA) were maintained in DMEM supplemented with $10 \%$ fetal bovine serum, $4 \mathrm{mM}$ glutamine, $100 \mathrm{U} / \mathrm{ml}$ penicillin and $100 \mu \mathrm{g} / \mathrm{ml}$ streptomycin and incubated at $37^{\circ} \mathrm{C}$ in a humidified atmosphere of $5 \% \mathrm{CO}_{2}$.

For the tumorsphere assay, single-cell suspensions were prepared at a density of 5,000 cells $/ \mathrm{ml}$ in condition-medium comprising serum-free DMEM/F12 supplemented with $100 \mathrm{IU} / \mathrm{ml}$ penicillin, $100 \mu \mathrm{g} / \mathrm{ml}$ streptomycin, $20 \mathrm{ng} / \mathrm{ml}$ human recombinant epidermal growth factor, $10 \mathrm{ng} / \mathrm{ml}$ human recombinant basic fibroblast growth factor, $2 \%$ B27 supplement without vitamin A and 1\% N2 supplement (Invitrogen Life Technologies), which were then seeded into ultra low attachment six-well plates (Corning Inc., Corning, NY, USA) at a density of 3,000 cells $/ \mathrm{ml}$. The suspension cultures were continued for six days until the formation of tumor spheres. To propagate the spheres in vitro, the sphere cells were collected by centrifugation $\left(300 \mathrm{xg}, 6 \mathrm{~min}, 4^{\circ} \mathrm{C}\right)$, dissociated into single-cell suspensions and cultured to enable the regeneration of spheres. Third generation spheres were used for all subsequent experiments.

To investigate the percentage of single cells able to regenerate new spheres, the cells were seeded at a density of 1,000 cells $/ \mathrm{ml}$ in a six-well plate to obtain new spheres. The total number of tumor spheres was counted after six days of culture. The efficiency of sphere formation was calculated using the following formula: Total number of spheres formed / total number of live cells seeded x 100 .

Small interfering (si)RNA and plasmid DNA transfection. The CK2 $\alpha$-specific siRNA and control RNA were purchased from Thermo Fisher Scientific (Waltham, MA, USA). In brief, the cells were seeded into six-well plates at $10^{5}$ cells/well one day prior to transfection, with a target of $30-50 \%$ confluency at the time of transfection. The cells were transfected with $50 \mathrm{nmol} / 1$ siRNA using Lipofectamine RNAiMAX (Invitrogen Life Technologies) according to the manufacturer's instructions. Adequate inhibition of the siRNA-mediated-knockdown was confirmed using western blot analysis. The pcDNA3.1-CK $2 \alpha$ or control pcDNA3.1-LacZ plasmid vectors were then transfected into the SKOV3 cells or SKOV3-derived SFCs $(0.5 \mu \mathrm{g} / \mathrm{ml}$ in a 24-well plate) using Lipofectamine 2000 transfection reagent (Invitrogen Life Technologies), according to the manufacturer's instructions. The cells were harvested for western blot analysis and tumorsphere formation assay.

Western blot analysis. The cells were lysed in buffer containing $50 \mathrm{mM}$ Tris- $\mathrm{HCl}$ (pH 7.5), $137 \mathrm{mM} \mathrm{NaCl}, 1 \%$ (w/v) SDS, $0.5 \mathrm{mM}$ phenylmethanesulfonyl fluoride, $2 \mu \mathrm{g} / \mathrm{ml}$ leupeptin, $2 \mu \mathrm{g} / \mathrm{ml}$ aprotinin and $1 \mathrm{mM}$ dithiothreitol. The cell lysate, containing $50 \mu \mathrm{g}$ protein, was separated by $12.5 \%$ SDS-PAGE and then blotted onto polyvinylidene difluoride membranes (Millipore). The murine monoclonal anti-CK2 $\alpha$ immunoglobulin (Ig)G at 1:2,000 dilution (Santa Cruz Biotechnology, Inc., Dallas, TX, USA), murine monoclonal anti-Gli1 IgG at 1:2,000 dilution (Santa Cruz Biotechnology, Inc.) and monoclonal anti- $\beta$-actin at 1:1,000 dilution (Sigma-Aldrich) antibodies were used as primary antibodies. Signals were detected using the enhanced chemiluminescence (ECL plus) detection kit (Amersham Pharmacia Biotech, Piscataway, NJ, USA). Images were scanned by transmission scanner (E85 Plus; Unisplendour Corp., Ltd, Beijing, China) followed by densitometric analysis using Alphazmager 2200 software (Silk Scientific, Orem, UT, USA).

Statistical analysis. Data are expressed as the mean \pm standard deviation for triplicate experiments and were analyzed using Student's t-test (SPSS software, version 15.0 for Windows; SPSS, Inc., Chicago, IL, USA). P<0.05 was considered to indicate a statistically significant difference.

\section{Results}

Apigenin inhibits the self-renewal of SKOV3-derived SFCs. Self-renewal capacity is one of the main characteristics of cancer stem cells (CSCs) (24). Therefore, the present study examined whether apigenin inhibited the self-renewal capability of OCSLCs isolated from the human SKOV3 cell line by measuring sphere formation. OCSLCs were grown in cancer stem cell condition-medium in suspension and treated with apigenin. At the end of the incubation period, images of the spheroids in each well were captured. The results revealed that apigenin decreased the size of the spheroids in suspension in a dose-dependent manner (Fig. 1A). The spheroids from each treatment group were then collected and resuspended to evaluate the sphere formation efficiency. The results demonstrated that apigenin inhibited the sphere formation efficiency of the SKOV3-derived SFCs in a dose-dependent manner (Fig. 1B). These results demonstrated that apigenin effectively inhibited the self renewal of SKOV3-derived SFCs, suggesting that apigenin was able to suppress the growth of OCSLCs.

Apigenin downregulates the expression of $C K 2 \alpha$ and Gli1 proteins in SKOV3-derived SFCs. Protein kinase CK2 is 
$\mathbf{A}$

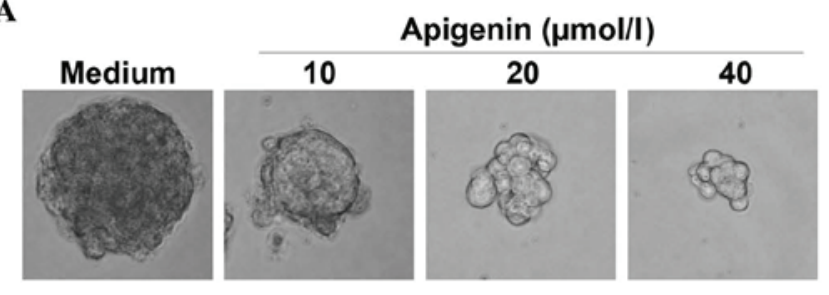

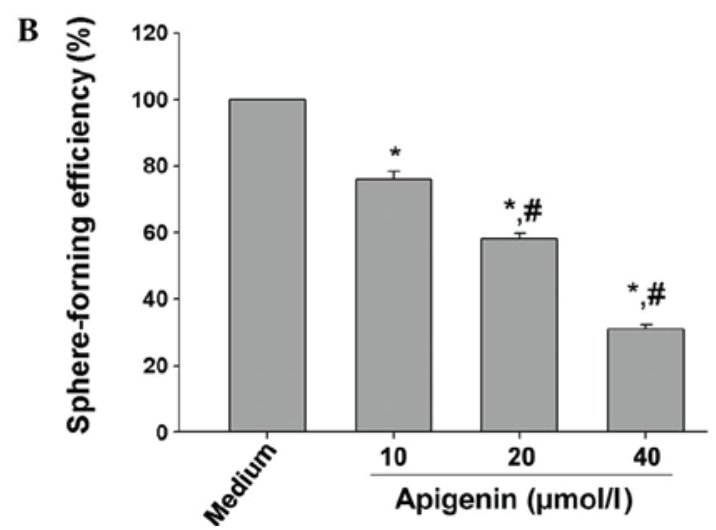

Figure 1. Apigenin inhibits the self-renewal of SKOV3-derived SFCs. (A) Apigenin decreased the size of spheroids in suspension in a dose-dependent manner (magnification, $\mathrm{x} 400$ ). (B) Apigenin inhibited the sphere formation efficiency of SKOV3-derived SFCs in a dose-dependent manner. ${ }^{*} \mathrm{P}<0.05$, compared with the control group; ${ }^{\#} \mathrm{P}<0.05$, for the comparison between the groups treated with 20 or $40 \mu \mathrm{mol} / 1$ apigenin and the group treated with $10 \mu \mathrm{mol} / 1$ apigenin. SFC, sphere-forming cell; Medium, control group.

A

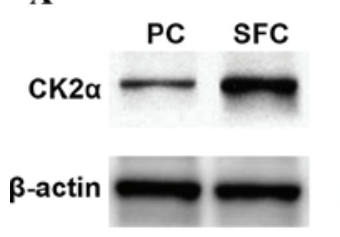

C

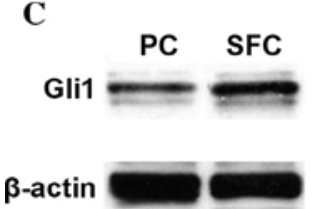

\section{B}

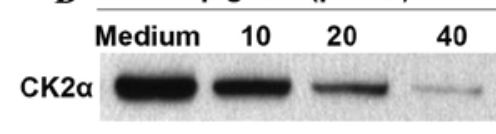

$\beta$-actin

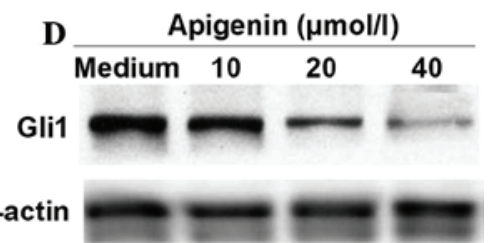

Figure 2. Apigenin downregulates the protein expression of CK2 $\alpha$ and Gli1 in SKOV3-derived SFCs. (A) CK $2 \alpha$ expression was higher in the SKOV3-derived SFCs than in the PCs. (B) Apigenin downregulated the expression of CK $2 \alpha$ in SKOV3-derived SFCs in a dose-dependent manner. (C) Expression of Gli1 was higher in SKOV3-derived SFCs compared with PCs. (D) Apigenin downregulated the expression of Gli1 in SKOV3-derived SFCs in a dose-dependent manner. CK2 $\alpha$, casein kinase $2 \alpha$; Gli1, glioma-associated oncogene 1; SFC, sphere forming cell; PC, parental cell; Medium, control group.

frequently activated in various types of human cancer. The activation of CK2 $\alpha$ is involved in the activation of the $\mathrm{Hh} / \mathrm{Gli} 1$ pathway and is associated with the stemness maintenance of CSCs (10). The protein expression of CK2 $\alpha$ was then compared between the parental cells and the SKOV3-derived SFCs. The results demonstrated that the expression of CK2 $\alpha$ was higher in the SKOV3-derived SFCs compared with that in the parental cells (Fig. 2A). In addition, the expression of CK2 $\alpha$ in the SKOV3-derived SFCs was downregulated by apigenin (Fig. 2B).

The Hh/Gli signaling pathway is important in the maintenance of stemness and tumorigenesis (11) and the inhibition of CK2 $\alpha$ causes downregulation in $\mathrm{Hh} / \mathrm{Gli}$ signaling, reducing human lung cancer cell stem-like side populations (10). Therefore, the present study compared the status of Gli1 protein expression between parental cells and SKOV3-derived SFCs. The effects of apigenin on the protein expression of Glil in

SKOV3-derived SFCs was also examined. As shown in Fig. 2C and D, elevated Gli1 protein expression was observed in the SKOV3-derived SFCs and apigenin reduced this expression in a dose-dependent manner.

Inhibition of CK2 $\alpha$ downregulates Glil and enhances apigenin-inhibited self-renewal of SKOV3-derived SFCs. Since CK2 $\alpha$ is highly expressed in CSCs compared with normal cells (25), the present study examined whether inhibition of CK2 $\alpha$ by siRNA enhanced the inhibitory effects of apigenin on sphere formation efficiency in SKOV3-derived SFCs. CK2 $\alpha$ siRNA inhibited the protein expression of CK2 $\alpha$ (Fig. 3A), apigenin $(20.0 \mu \mathrm{mol} / \mathrm{l})$ inhibited the sphere formation efficiency in the SKOV3-derived SFCs transfected with the scrambled siRNA (Fig. 3B) and the inhibition of CK2 $\alpha$ by siRNA further enhanced the inhibitory effects of $20.0 \mu \mathrm{mol} / 1$ apigenin on the sphere formation efficiency of SKOV3-derived SFCs (Fig. 3B). These results provided mechanistic evidence that apigenin-inhibited self-renewal was, in part, due to the inactivation of CK2 $\alpha$ in the SKOV3-derived SFCs.

To investigate whether CK2 suppression had an effect on the Hh pathway, the expression of CK2 was silenced using CK2 $\alpha$-specific siRNAs. The results of western blot analysis confirmed that silencing of CK2 $\alpha$ significantly inhibited the expression of Gli1 in the SKOV3-derived SFCs (Fig. 3A).

Overexpression of CK2 $\alpha$ leads to Glil upregulation and attenuates apigenin-inhibited self-renewal in SKOV3-derived SFCs. To confirm whether CK2 $\alpha$ activity affected the expression of Gli1 and sphere-forming capability of the SKOV3 cells and its sphere forming capability, SKOV3 cells were transfected with either a pcDNA3.1-CK2 $\alpha$ or a control pcDNA3.1-LacZ plasmid. Western blot analysis revealed that upregulation of $C K 2 \alpha$ by pcDNA3.1-CK $2 \alpha$ transfection resulted in overexpression of the CK2 $\alpha$ protein in the SKOV3 cells (Fig. 4A). Elevated Gli1 protein levels were also observed in the SKOV3 cells that exhibited ectopic overexpression of CK2 $\alpha$ (Fig. 4A). In addition, the tumor sphere formation assay revealed that overexpression of the CK2 $\alpha$ protein increased the sphere formation of SKOV3 cells (Fig. 4B). These findings suggested that the overexpression of the $C K 2 \alpha$ gene leads to an upregulation 

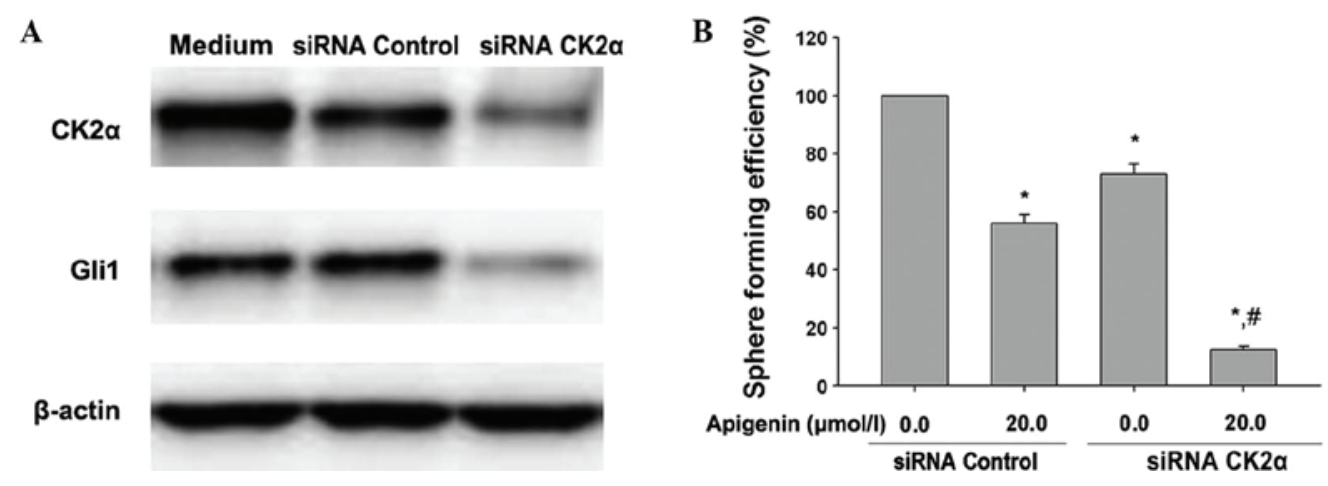

Figure 3. Inhibition of CK2 $\alpha$ downregulates Gli1 and enhances the apigenin-inhibition of self-renewal of the SKOV3-derived SFCs. (A) CK2 $\alpha$ siRNA inhibited the protein expression of CK $2 \alpha$ and Gli1. (B) Inhibition of CK2 $2 \alpha$ by siRNA further enhanced the inhibitory effects of apigenin (20.0 $\mu$ mol/l) on the sphere-forming efficiency of SKOV3-derived SFCs. ${ }^{*} \mathrm{P}<0.05$, compared with the control group $\left(0 \mu \mathrm{mol} / 1\right.$ apigenin with CK2 $\alpha$ siRNA control); ${ }^{"} \mathrm{P}<0.05$, compared with the groups treated with $20 \mu \mathrm{M} / 1$ apigenin or CK2 $\alpha$ siRNA alone. CK2 $\alpha$, casein kinase 2 $\alpha$; Gli1, glioma-associated oncogene 1; SFC, sphere forming cell; Medium, control group.

A
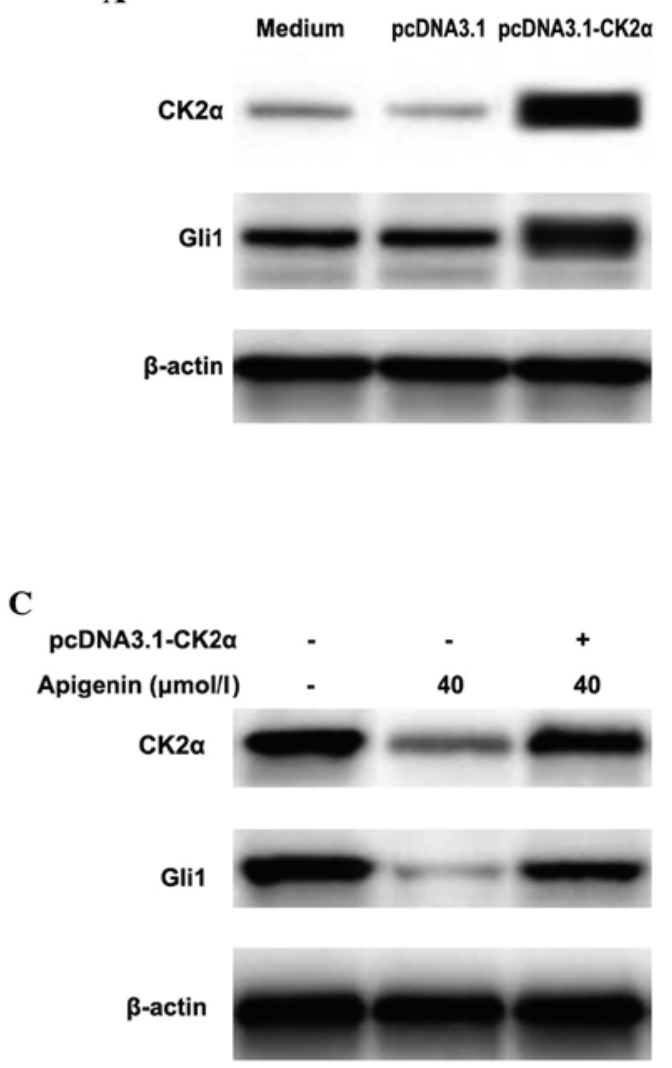

B
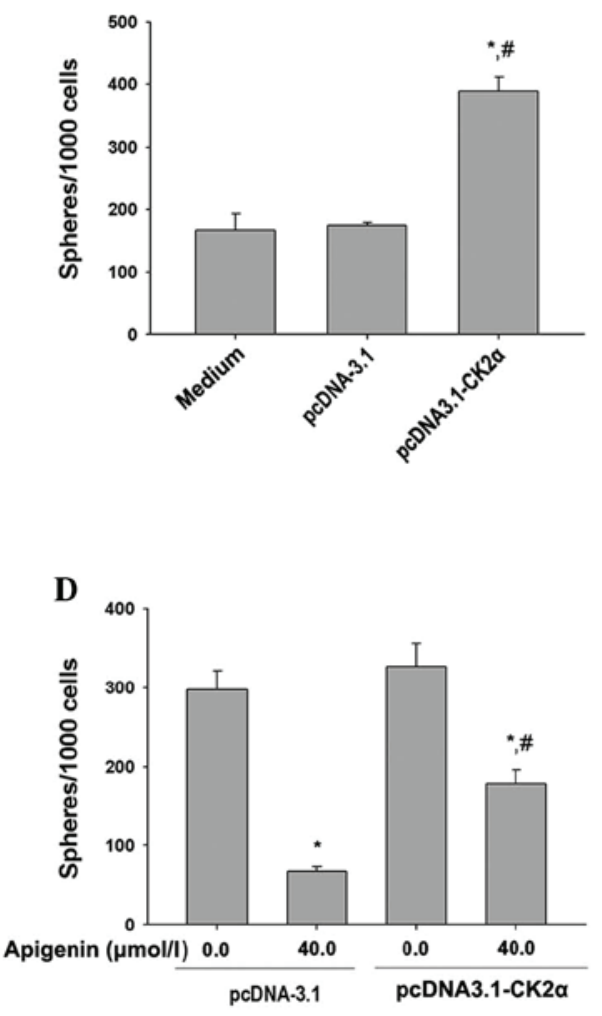

Figure 4. Overexpression of CK2 $\alpha$ leads to Gli1 upregulation and attenuates apigenin inhibiting self-renewal in SKOV3-derived SFCs. (A) Gli1 protein expression increased in the SKOV3 cells transfected with pcDNA3.1-CK2 $\alpha$. (B) Overexpression of CK2 $\alpha$ protein increased the sphere formation of the SKOV3 cells. ${ }^{*} \mathrm{P}<0.05$, compared with the pcDNA3.1 group and medium (control) group; ${ }^{*} \mathrm{P}<0.05$, compared with the pcDNA3.1 group. (C) Overexpression of CK2 $\alpha$ attenuated the apigenin-induced downregulation of $\mathrm{CK} 2 \alpha$ and Gli1 protein expression. (D) Overexpression of CK2 $\alpha$ reduced the inhibition of sphere formation by apigenin in the SKOV3-derived SFCs. " $\mathrm{P}<0.05$, compared with the control group $(0 \mu \mathrm{mol} / 1$ apigenin+pcDNA3.1); $\mathrm{P}<0.05$, compared with the pcDNA3.1 group. CK2 $\alpha$, casein kinase $2 \alpha$; Gli1, glioma-associated oncogene 1; SFC, sphere forming cell; Medium, control group.

in the expression of Gli1 and a potentiation in the self-renewal capacity of SKOV3-derived SFCs.

In addition, the overexpression of CK2 $\alpha$ attenuated the apigenin-induced downregulation of CK2 $\alpha$ and Glil protein expression (Fig. 4C) and reduced its inhibition of sphere formation in the SKOV3-derived SFCs (Fig. 4D). These results corroborated that apigenin-inhibited self-renewal is, in part, due to the inactivation of CK2 $\alpha$ and the sequential downregulated expression levels of Gli1 in SKOV3-derived SFCs.

\section{Discussion}

The results of the present study suggested that apigenin inhibits the self-renewal capacity of SKOV3-derived SFCs 
via downregulation of Gli1 expression by the inhibition of CK2 $\alpha$. This was supported by several lines of evidence. Firstly, apigenin inhibited the sphere formation efficiency of SKOV3-derived SFCs, accompanied by a downregulation of the expression of CK2 $\alpha$ and Gli1. Secondly, the inhibition of CK $2 \alpha$ by siRNA acted synergistically with apigenin in downregulating the expression of CK $2 \alpha$ and Gli1 as well as inhibiting the self-renewal capability of SKOV3-derived SFCs. Finally, the forced overexpression of CK $2 \alpha$ resulted in an increase in the expression levels of CK2 $\alpha$ and Gli1 and enhanced the percentage of sphere formation in the parental SKOV3 cells. This forced overexpression of CK $2 \alpha$ also attenuated the apigenin-inhibited self-renewal capability of the SKOV3-derived SFCs.

There is no previous evidence for a correlation between CK2 and Hh/Gli signaling in human ovarian cancer cells, although CK2 has been suggested as a positive regulator of the Hh signal transduction pathway and led to the phosphorylation of two serine residues in Smo in Drosophila (26). However, several studies have suggested that Smo in mammals and Drosophila are regulated by distinct mechanisms $(27,28)$. Chen et al (29) demonstrated that mammalian Smo are activated by multi-site phosphorylation by CK1 $\alpha$ and GRK2 and the mechanism for Smo phosphorylation in mammalian cells was considered to proceed via two steps. The results of the present study indicated that CK $2 \alpha$ silencing reduced the expression of Gli1 protein in SKOV3-derived SFCs and the forced overexpression of CK $2 \alpha$ resulted in an increase in the expression of Gli1 protein in parental SKOV3 cells. These data suggested that CK $2 \alpha$ may regulate Gli1 in human ovarian cancer cells in a similar manner to that present in Drosophila. Jia et al (26) demonstrated that Gli1 is directly phosphorylated by CK2 in Drosophila, preventing the ubiquitination and degradation of Gli1. Although the mechanism underlying CK2 regulation in types of human cancer remains to be elucidated, there is evidence suggesting that CK2 is essential in Wnt/ $\beta$-catenin signaling $(30,31)$. Further studies are required to elucidate the precise mechanisms.

The Hh pathway may be important in the maintenance of CSCs; however, drug targeting of the Hh pathway is limited. CK2 provides an additional target for inhibition of $\mathrm{Hh} / \mathrm{Gli}$ signaling. There has been little development of CK2 inhibitors as therapeutic agents, partially due to the adenosine triphosphate binding pocket of CK2 differing from other protein kinase agents $(32,33)$. Only one small molecule CK2 inhibitor, CX-4945, has been used in clinical trials as a potential anticancer drug. CX-4945 selectively inhibits CK2 and is a promising oral therapeutic agent for multiple types of human cancer, which has demonstrated a favorable safety profile in the initial phase of clinical trials (34). In addition, a synthetic peptide-based drug, which targets the CK2 phosphoacceptor domain, termed CIGB-300, has been identified as safe and of clinical benefit in the initial phase of cervical cancer trials (35).

As a selective CK2 kinase inhibitor, apigenin has been demonstrated to induce cell death in ovarian cancer cells and reduce the risk of ovarian cancer. The present study provided the first evidence, to the best of our knowledge, that apigenin inhibits the self-renewal capacity of SKOV3-derived SFCs through downregulation of the expression of Gli1 by inhibiting CK2 $\alpha$. Due to the emerging importance of $\mathrm{Hh} / \mathrm{Gli}$ signaling in tumor initiation and progression, these results provide important evidence for the potential benefits of CK2 inhibitors, including apigenin.

\section{Acknowledgements}

The authors would like to thank Professor Jian-Guo Cao and Dr Xi-Yun Deng (Medical College, Hunan Normal University, Changsha, Hunan, China) for their critical input into the scientific content. The present study was supported by the Construct Program of the Key Discipline of Basic Medicine in Hunan Province, the Youth Fund of Hunan Normal University (grant no. 110637) and the Project of Hunan Provincal Natural Science Foundation (grant no. 13JJ3061).

\section{References}

1. Meggio F and Pinna LA: One-thousand-and-one substrates of protein kinase CK2? FASEB J 17: 349-368, 2003.

2. Raaf J, Bischoff N, Klopffleisch K, et al: Interaction between CK2alpha and CK2beta, the subunits of protein kinase CK2: thermodynamic contributions of key residues on the CK2alpha surface. Biochemistry 50: 512-522, 2011.

3. Buchou T, Vernet M, Blond O, et al: Disruption of the regulatory beta subunit of protein kinase CK2 in mice leads to a cell-autonomous defect and early embryonic lethality. Mol Cell Biol 23: 908-915, 2003.

4. Ahmad KA, Wang G, Unger G, Slaton J and Ahmed K: Protein kinase CK2 - a key suppressor of apoptosis. Adv Enzyme Regul 48: 179-187, 2008.

5. Piazza FA, Ruzzene M, Gurrieri C, et al: Multiple myeloma cell survival relies on high activity of protein kinase CK2. Blood 108: 1698-1707, 2006.

6. Prudent R, Moucadel V, Nguyen CH, et al: Antitumor activity of pyridocarbazole and benzopyridoindole derivatives that inhibit protein kinase CK2. Cancer Res 70: 9865-9874, 2010.

7. Dominguez I, Sonenshein GE and Seldin DC: Protein kinase CK2 in health and disease: CK2 and its role in Wnt and NF-kappaB signaling: linking development and cancer. Cell Mol Life Sci 66: 1850-1857, 2009.

8. Duncan JS and Litchfield DW: Too much of a good thing: the role of protein kinase $\mathrm{CK} 2$ in tumorigenesis and prospects for therapeutic inhibition of CK2. Biochim Biophys Acta 1784: 33-47, 2008.

9. Guerra B: Protein kinase $\mathrm{CK} 2$ subunits are positive regulators of AKT kinase. Int J Oncol 28: 685-693, 2006.

10. Zhang S, Wang Y, Mao JH, et al: Inhibition of CK $2 \alpha$ down-regulates Hedgehog/Gli signaling leading to a reduction of a stem-like side population in human lung cancer cells. PLoS One 7: e38996, 2012.

11. Varjosalo $\mathbf{M}$ and Taipale J: Hedgehog: functions and mechanisms. Genes Dev 22: 2454-2472, 2008

12. Ingham PW, Nakano Y and Seger C: Mechanisms and functions of Hedgehog signalling across the metazoa. Nat Rev Genet 12: 393-406, 2011.

13. Ng JM and Curran T: The Hedgehog's tale: developing strategies for targeting cancer. Nat Rev Cancer 11: 493-501, 2011.

14. Takebe N, Harris PJ, Warren RQ and Ivy SP: Targeting cancer stem cells by inhibiting Wnt, Notch, and Hedgehog pathways. Nature Rev Clin Oncol 8: 97-106, 2011.

15. Ruiz i Altaba A: Therapeutic inhibition of Hedgehog-GLI signaling in cancer: epithelial, stromal, or stem cell targets? Cancer Cell 14: 281-283, 2008.

16. Kinzler KW, Bigner SH, Bigner DD, et al: Identification of an amplified, highly expressed gene in a human glioma. Science 236: 70-73, 1987.

17. Epstein EH: Basal cell carcinomas: attack of the hedgehog. Nature Rev Cancer 8: 743-754, 2008.

18. Ciucci A, De Stefano I, Vellone VG, et al: Expression of the glioma-associated oncogene homolog 1 (gli1) in advanced serous ovarian cancer is associated with unfavorable overall survival. PloS One 8: e60145, 2013. 
19. Shukla S and Gupta S: Apigenin-induced cell cycle arrest is mediated by modulation of MAPK, PI3K-Akt, and loss of cyclin D1 associated retinoblastoma dephosphorylation in human prostate cancer cells. Cell Cycle 6: 1102-1114, 2007.

20. Shukla S and Gupta S: Suppression of constitutive and tumor necrosis factor alpha-induced nuclear factor (NF)-kappaB activation and induction of apoptosis by apigenin in human prostate carcinoma PC-3 cells: correlation with down-regulation of NF-kappaB-responsive genes. Clin Cancer Res 10: 3169-3178, 2004.

21. Chen D, Landis-Piwowar KR, Chen MS and Dou QP: Inhibition of proteasome activity by the dietary flavonoid apigenin is associated with growth inhibition in cultured breast cancer cells and xenografts. Breast Cancer Res 9: R80, 2007.

22. Way TD, Kao MC and Lin JK: Degradation of HER $2 /$ neu by apigenin induces apoptosis through cytochrome c release and caspase-3 activation in HER2/neu-overexpressing breast cancer cells. FEBS Lett 579: 145-152, 2005.

23. Feng $X$, Zhou Q, Liu C and Tao ML: Drug screening study using glioma stem-like cells. Mol Med Rep 6: 1117-1120, 2012.

24. Castellanos JA, Merchant NB and Nagathihalli NS: Emerging targets in pancreatic cancer: epithelial-mesenchymal transition and cancer stem cells. Onco Targets Ther 6: 1261-1267, 2013.

25. Bae KM, Su Z, Frye C, et al: Expression of pluripotent stem cell reprogramming factors by prostate tumor initiating cells. J Urol 183: 2045-2053, 2010.

26. Jia H, Liu Y, Xia R, et al: Casein kinase 2 promotes Hedgehog signaling by regulating both smoothened and Cubitus interruptus. J Biol Chem 285: 37218-37226, 2010.
27. Varjosalo M, Li SP and Taipale J: Divergence of hedgehog signal transduction mechanism between Drosophila and mammals. Dev Cell 10: 177-186, 2006.

28. Huangfu D and Anderson KV: Signaling from Smo to $\mathrm{Ci} / \mathrm{Gli}$ : conservation and divergence of Hedgehog pathways from Drosophila to vertebrates. Development 133: 3-14, 2006.

29. Chen Y, Sasai N, Ma G, et al: Sonic Hedgehog dependent phosphorylation by CK1alpha and GRK2 is required for ciliary accumulation and activation of smoothened. PLoS Biol 9: e1001083, 2011.

30. Sarno $\mathrm{S}$ and Pinna LA: Protein kinase CK2 as a druggable target. Mol Biosyst 4: 889-894, 2008.

31. Gao Y and Wang HY: Casein kinase 2 is activated and essential for Wnt/beta-catenin signaling. J Biol Chem 281: 18394-18400, 2006.

32. Cozza G, Meggio F and Moro S: The dark side of protein kinase CK2 inhibition. Curr Med Chem 18: 2867-2884, 2011.

33. Cozza G, Bortolato A and Moro S: How druggable is protein kinase CK2? Med Res Rev 30: 419-462, 2010.

34. Pierre F, Chua PC, O'Brien SE, et al: Pre-clinical characterization of CX-4945, a potent and selective small molecule inhibitor of CK2 for the treatment of cancer. Mol Cell Biochem 356: 37-43, 2011.

35. Perea SE, Baladron I, Garcia Y, et al: CIGB-300, a synthetic peptide-based drug that targets the CK2 phosphoaceptor domain. Translational and clinical research. Mol Cell Biochem 356: 45-50, 2011. 